\title{
The synchronous occurrence of squamous cell carcinoma and gastrointestinal stromal tumor (GIST) at esophageal site Gian Paolo Spinelli1,2, Evelina Miele ${ }^{1}$, Federica Tomao ${ }^{3}$, Luigi Rossi², Giulia Pasciuti², Angelo Zullo4, Federica Zoratto ${ }^{2}$, Jose Nunnari ${ }^{5}$, Giovanni Codacci Pisanelli1,2 and Silverio Tomao*1,2
}

\author{
Address: ${ }^{1}$ Department of Experimental Medicine, University of Rome "Sapienza", Rome, Italy, ${ }^{2}$ Universitary Oncology, S.M Goretti Hospital, \\ Latina, Italy, ${ }^{3}$ Department of Gynaecology Perinatology and Puericulture Science, University of Rome "Sapienza", Rome, Italy, ${ }^{4}$ Gastroenterology \\ and Digestive Endoscopy, "Nuovo Regina Margherita" Hospital, Rome, Italy and ${ }^{5}$ Pathologic Anatomy, San Camillo-Forlanini Hospital, Rome, \\ Italy \\ Email: Gian Paolo Spinelli - gianpaolo.spinelli@uniroma1.it; Evelina Miele - evelina.miele@uniroma1.it; \\ Federica Tomao - tomao.smfa@tiscali.it; Luigi Rossi - gigireds.s@libero.it; Giulia Pasciuti - giulia.pasciuti@libero.it; \\ Angelo Zullo - giaggio.s@libero.it; Federica Zoratto - federica.z@libero.it; Jose Nunnari - tremotti@sancamilloforlanini.rm.it; \\ Giovanni Codacci Pisanelli - giovanni.codacci@uniroma1.it; Silverio Tomao* - silverio.tomao@uniroma1.it \\ * Corresponding author
}

Published: 5 November 2008

World Journal of Surgical Oncology 2008, 6:116 doi:10.1186/1477-7819-6-116

This article is available from: http://www.wjso.com/content/6/1/116

(c) 2008 Spinelli et al; licensee BioMed Central Ltd.

This is an Open Access article distributed under the terms of the Creative Commons Attribution License (http://creativecommons.org/licenses/by/2.0), which permits unrestricted use, distribution, and reproduction in any medium, provided the original work is properly cited.
Received: 20 February 2008

Accepted: 5 November 2008

\begin{abstract}
Background: Esophageal squamous cell carcinoma is a relative common malignancy with a very poor prognosis, even adopting an integrated and multidisciplinary approach. According to the literature, gastrointestinal stromal tumors (GISTs) rarely originate from the esophagus. Moreover there are not reports of synchronous occurrence of squamous cell carcinoma and GIST at esophageal site.
\end{abstract}

Case presentation: We describe a case of a 74 year old patient who underwent surgery for squamous cell carcinoma of the lower third of the esophagus with an incidental pathologic diagnosis of a concomitant GIST in the thoracic tract.

Conclusion: In literature there is no evidence of concomitant squamous carcinoma and GIST of the thoracic esophagus, even if esophageal GISTs are sometimes described. The occasional finding of this neoplastic lesion underlines the importance of a carefully pathological diagnosis for its identification. Surgery, followed by a multidisciplinary approach remains the first-line treatment in both squamous and stromal neoplasm.

\section{Background}

GISTs are the most frequent non epithelial neoplasms of the gastrointestinal tract, with a preferred gastric localization (about $60 \%$ in the stomach and $20-30 \%$ in the intestine). The esophageal location is very uncommon and represents approximately $5 \%$ of gastrointestinal GISTs. In addition, the majority of esophageal GISTs arise at the gas- tro-esophageal junction; therefore a GIST located at the level of the thoracic esophagus is extremely rare. Many esophageal GISTs are diagnosed after the onset of clinical symptoms, or sometimes discovered by chance, during routine examinations (diagnostic endoscopy procedures, transesophageal echocardiograms or surgical procedures carried out for other reasons). The diagnosed incidentally 
GISTs tend to be smaller in terms of centimetres and they already present the mutation at the KIT level. The elective treatment for these tumors is esophagectomy, paying particular attention to excision of the mucosa, sub mucosa and the muscular areas and of the surrounding periesophageal tissues.

\section{Case presentation}

We describe a case of a 74 year old male patient, affected by a myeloproliferative syndrome. At the age of 26 he underwent a surgical gastrectomy for a hemorrhage caused by a perforated ulcer. Later, in December 2006, an upper gastrointestinal endoscopy revealed a neoplasm at the level of the thoracic esophagus. Multiple tissue biopsies histologically showed a scarcely differentiated squamous cell carcinoma. Subsequently all the necessary staging exams, including a total body Computed Tomography (CT) were performed. The CT did not show any suspected lymph nodes nor other lesions. In March 2007 the patient underwent a total esophagectomy and an esophago-gastroplasty with colon interposition for replacement of the esophagus.

\section{Histological examination}

The final histological findings confirmed the diagnosis of infiltrating squamous cell carcinoma; (Figure 1,A, B). The lesion extended into the sub mucosal layer, a grade G3 was diagnosed and the surgical margins were considered free of infiltration. Since the regional lymph nodes were not reported, the final staging was pT1 pNx. In addition, a sample was taken at a distance from the original tumor as an occasional finding in the esophageal muscular tunica. This showed a fused cellular intramural micro nodule with a maximum diameter of $0.2 \mathrm{~cm}$, and with morphological characteristics suggesting a very low risk GIST (Figure $2 \mathrm{~A}, \mathrm{~B})$.

The immunohistochemistry of the fused cells showed an intense and diffuse positivity for CD117, CD34 and CD99 and negative results for $\mathrm{S} 100$, desmin and actin (Figure $3 \mathrm{~A}, \mathrm{~B})$. The proliferate index Ki 67 was less than 5\% with 4 mitoses per $50 \mathrm{HPF}$.

The aspects of this lesion reminded palisading-vacuolated spindle cell GISTs. In fact it showed nuclear palisading, resembling peripheral schwannomas and the typical feature of prominent perinuclear vacuolization.

In May 2007, a total body CT scan showed the presence of necrotic-hemorrhagic foci, of probable ischemic nature, in the cortical and sub cortical brain regions. At the same time, the thoracic region showed the presence of diffuse micro nodules in the lungs, associated with chronic bronchial and peribronchial wall thickening. We also noticed a modest splenomegaly $(22 \mathrm{~cm})$ and, at the aortic-pulmonary window, in the inferior pre-tracheal and right hilum areas, several lymph nodes of $13 \mathrm{~mm}$. Considering the pathological and clinical staging, the patient did not require chemotherapy treatment, and would continue his follow-up with routine examinations.

\section{Discussion}

The term Gastric Stromal Tumors was first coined in 1983 by Mazur and Clark [1], to describe a heterogeneous group of mesenchimal tumors that did not exhibit classic features of muscular differentiation. However only in
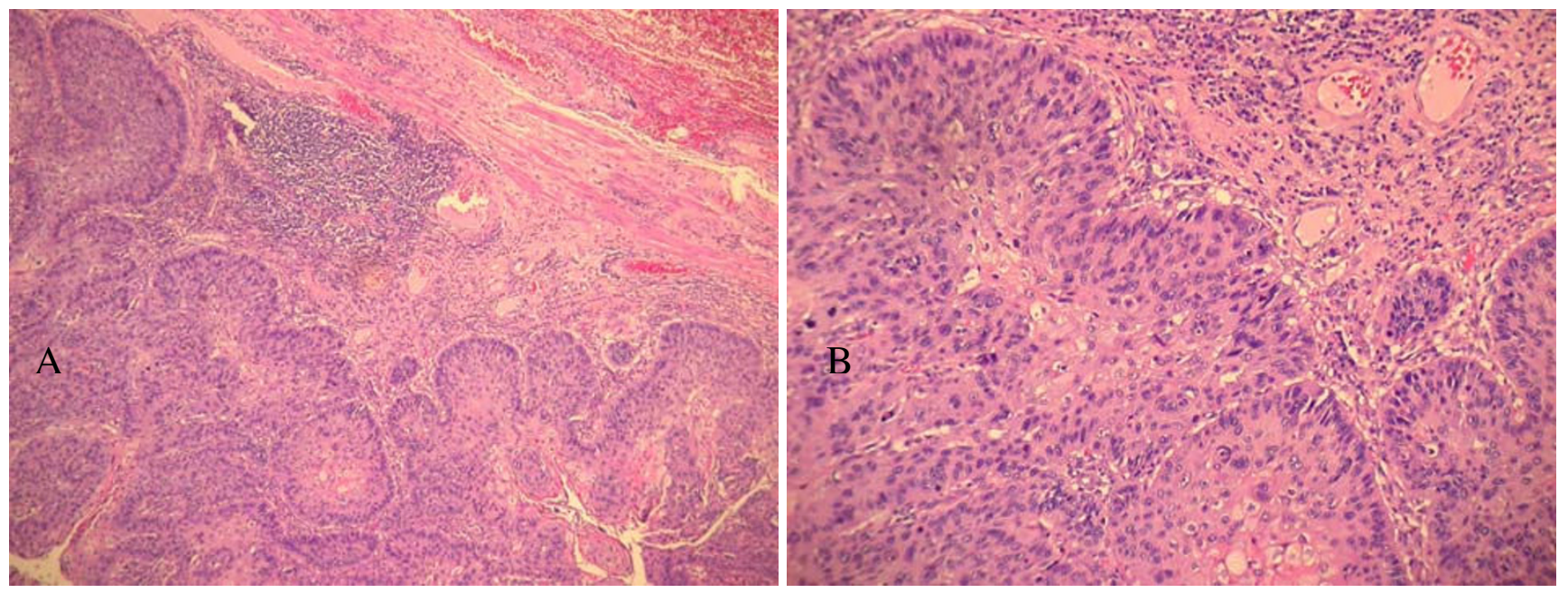

\section{Figure I}

Microscopic examination of squamous cell carcinoma. A) Esophagus infiltrative squamous cell carcinoma ( $H$ and $E$ I0x); B) Esophagus infiltrative squamous cell carcinoma (H \& E 20x); 

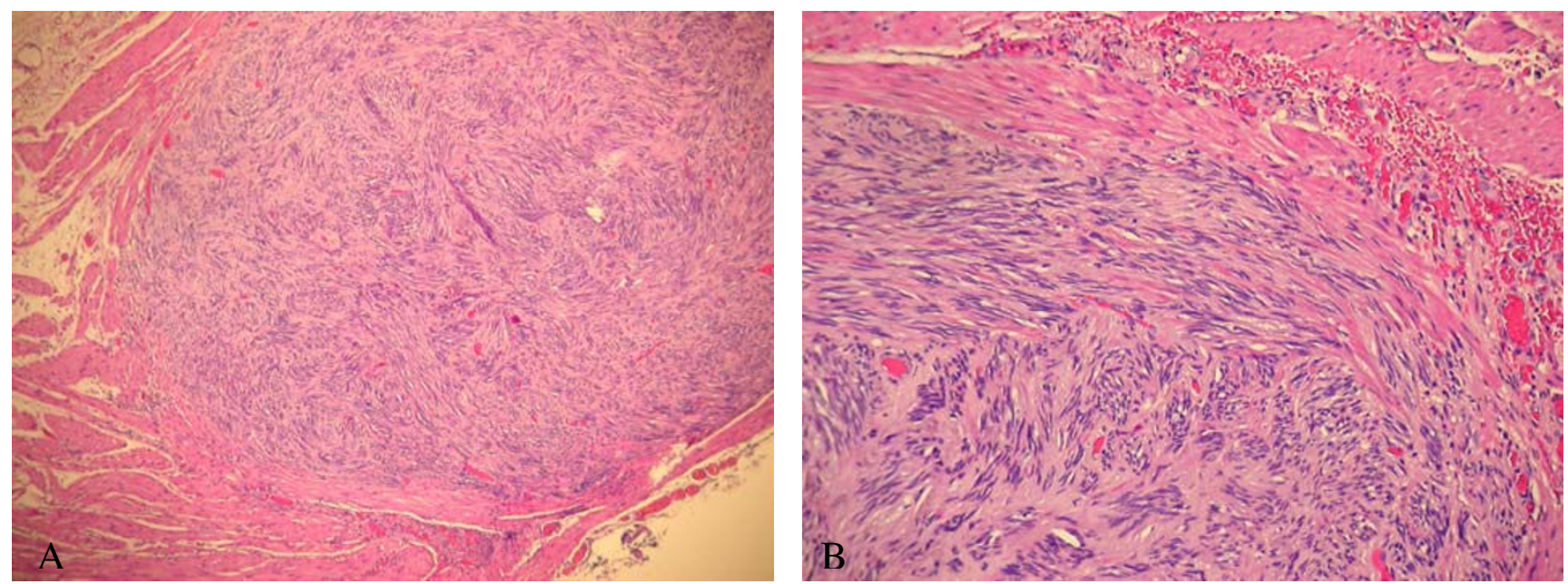

\section{Figure 2}

Microscopic examination of GIST. A) Intramural nodule of gastrointestinal stromal tumour (GIST) (H \& E I0x); B) Fascicular arrangement of spindle cells with prominent nuclear palisade in GIST (H \& E IOx);

1998 Kindblom et al [2], revealed the expression of the antigen CD 117 and Hirota et al. [3], first identified a gain of function mutations at the level of the proto-oncogene c-KIT (CD 117) in this neoplasm, which is regarded to be pivotal in the development of most GISTs. These very suggestive neoplasias are extremely rare and tend to be localized at the gastric level (60-70\%) and small intestine (20$30 \%$ ); with smaller percentages these lesions have been described in other regions such as the large intestine, rectum, and omentum and with an incidence of less than 5\% in the esophagus [4].
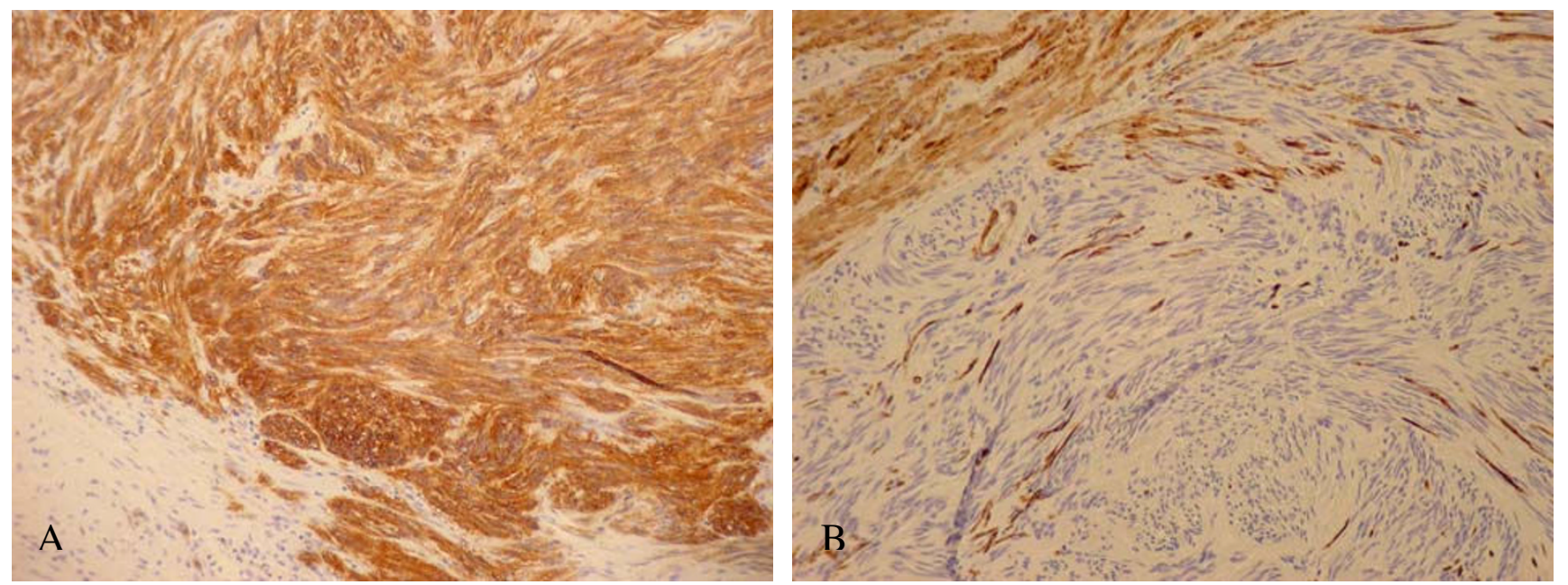

The median age of onset is 60-69 years and the symptoms are usually non-specific such as tiredness, abdominal discomfort and gastro-intestinal bleeding. The main instruments used for the diagnosis of GISTs are CT scans and PET scans.

${ }^{18}$ F-FDG PET seems to have lower sensitivity than CT for gastrointestinal stromal tumors staging. However PET is superior in monitoring therapeutic treatment response to imatinib in patients with malignant GISTs. CT and PET are complementary and PET/CT techniques have been

\section{Figure 3}

Immuno - staining of GIST. A) KIT (CDI I7) immuno-staining in GIST. The tumor cells show strong cytoplasmic and perinuclear positivity; B) Negative immuno-staining for Desmin in GIST. 
shown to be useful in diagnosis, staging and treatment response in GISTs [5-7]. Based on parameters such as size and number of mitosis, these neoplasias can be subdivided into different risk classes: high, intermediate, low and very low.

Positivity for the CD117 is the key feature of GIST, but CD34 and nestin are other commonly expressed but less GIST-specific antigens. Moreover, these tumors can be positive for smooth muscle markers and generally negative for desmine. S-100 protein expression is rare and glial fibrillary acidic protein is not present. Keratine 18 and Keratine 8 are occasionally expressed.

CD99 is not required for GIST diagnosis, but as its immunoreactivity is not uncommon in a variety of soft tissue tumors, correlation of expression of this marker with that of other immunomarkers and with morphology is warranted [8].

Gastrointestinal (true) smooth muscle tumors, nerve sheath tumors, desmoids, inflammatory myofibroblastic tumors, inflammatory fibroid polyps, and undifferentiated sarcomas are the most commonly confused with GISTs. Rarely, poorly-differentiated carcinomas and histiocytic sarcoma can also take a part into differential diagnosis which is usually importantly aided by immonohistochemistry. These tumors have been reported as c-KIT negative but with other peculiar markers, generally not expressed in GISTs [9].

The differential diagnosis among GISTs and other epithelial neoplastic lesions of the gastro-intestinal tract is very important. In fact 95\% of these tumors express the transmembrane receptor with tyrosine kinase activity c-kit, and above all this group of lesions tends to show an interesting response (sometimes dramatic) to new target treatments [3,10-12].

Clinical studies have shown that the elective medical treatment for patients with inoperable lesions is imatinib (400 mg/die) with positive responses above 50\% [13]. The use of other treatments such as Sunitinib, another tyrosine kinase inhibitor, has been approved in patients who do not respond to treatment with imatinib, and generally present a mutation of the exon 9 of c-kit $[13,14]$.

Esophageal GISTs are rarely described in literature, and no cases of both GIST and squamous cell carcinoma have been reported. On the contrary, other kind of tumors have been found together (synchronous or metachronous) with GISTs in the gastrointestinal system, such as low grade malign lymphoma and GIST in stomach, colorectal cancer, gastric cancer, small bowel or mesenterium tumors and carcinoid of pancreas [15-18].
According to our epidemiological knowledge the hypothesis of a common etiopathogenesis at esophageal site, for GIST and esophageal squamous cell carcinoma cannot be supported. However we could hypothesize that development of these tumors may involve common carcinogen antigens, making the synchronous occurrence of GIST and other abdominal malignancy not only a coincidence.

\section{Conclusion}

Our case report seems to be the only one described in a patient with a myeloproliferative syndrome, esophageal squamous cell carcinoma and GIST. The occasional finding of this latter neoplastic lesion underlines once more the importance of a carefully pathological diagnosis and a multidisciplinary approach. Of course, surgery $[19,20]$ remains the first-line treatment in both squamous and stromal neoplasms.

\section{Consent}

Written consent was obtained from the patient for publication of this case report.

\section{Competing interests}

The authors declare that they have no competing interests.

\section{Authors' contributions}

GPS conceived of the study, partecipated in its design and drafting. EM conceived of the study, partecipated in its design and drafting. FT participated in the design of the study and collect the clinical data. LR participated in the design of the study and collect the clinical data. GP participated in the design of the study and collect the clinical data. AZ participated in the design of the study and collect the clinical data. FZ participated in the design of the study and collect the clinical data. GCP participated in the design of the study and collect the clinical data. JN carried out the histopathological evaluation. ST conceived of the study, participated in its design and coordination and helped to draft the manuscript. All authors read and approved the final manuscript.

\section{References}

I. Mazur MT, Clark HB: Gastric stromal tumors. Reappraisal of histogenesis. Am J Surg Pathol 1983, 7(6):507-519.

2. Kindblom LG, Remotti HE, Aldenborg F, Meis-Kindblom JM: Gastrointestinal pacemaker cell tumour (GIPACT): gastrointestinal Stromal tumors show phenotypic characteristics of the interstitial cells of Cajal. Am J Pathol I998, I 52(5): I 259-| 269.

3. Hirota S, Isozaki K, Moriyama $Y$, Hashimoto K, Nishida T, Ishiguro S, Kawano K, Hanada M, Kurata A, Takeda M, Muhammad Tunio G, Matsuzawa Y, Kanakura Y, Shinomura Y, Kitamura Y: Gain-of-function mutations of c-kit in human gastrointestinal stromal tumors. Science 1998, 279:577-80.

4. Corless CL, Fletcher JA, Heinrich MC: Biology of gastrointestinal stromal tumors. J Clin Oncol 2004, 22( 18):38| 3-3825.

5. Gayed I, Vu T, lyer R, Johnson M, Macapinlac M, Swanston N, Podoloff $D$ : The role of 18 F-FDG PET in staging and early prediction of response to therapy of recurrent gastrointestinal stromal tumors. J Nucl Med 2004, 45(I): 17-2I. 
6. Alberini JL, Al Nakib M, Wartski M, Gontier E, Cvitkovic F, Rixe O, Rougier P, Pecking AP: The role of PET scan in gastrointestinal stromal tumors. Gastroenterol Clin Biol 2007, 3 I (6-7):585-93.

7. Goldstein D, Tan BS, Rossleigh M, Haindl W, Walker B, Dixon J: Gastrointestinal stromal tumors: correlation of F-FDG gamma camera-based coincidence positron emission tomography with CT for the assessment of treatment response - an AGITG study. Oncology 2005, 69(4):326-32.

8. Shidham VB, Chivujula M, Gupta D, Rao RN, Komorowski R: Immunohistochemical comparison of gastrointestinal stromal tumor and solitary fibrous tumor. Arch Pathol Lab Med 2002, 126: I 189-1192.

9. Miettinen M, Lasota J: Gastrointestinal stromal tumors. Review on morphology, molecular pathology, prognosis and differential diagnosis. Arch Pathol Lab Med 2006, I 30: | 466- |478.

10. Fletcher CD, Berman JJ, Corless C, Gorstein F, Lasota J, Longley BJ, Miettinen M, O'Leary T], Remotti H, Rubin BP, Shmookler B, Sobin LH, Weiss SW: Diagnosis of gastrointestinal stromal tumors: a consensus approach. Hum Pathol 2002, 33:459-465.

II. Lux ML, Rubin BP, Biase TL, Chen CJ, Maclure T, Demetri G, Xiao S, Singer S, Fletcher CD, Fletcher JA: KIT extra cellular and kinase domain mutations in gastrointestinal stromal tumors. $\mathrm{Am} J$ Pathol 2000, 156:79|-795.

12. Rubin BP, Fletcher JA, Fletcher CD: Molecular insights into the histogenesis and pathogenesis of gastrointestinal stromal tumors. Int J Surg Pathol 2000, 8(I):5- I0.

13. Siehl J, Thiel E: C-kit, GIST, and imatinib. Recent Results Cancer Res 2007, I 76: |45-I5I.

14. Fletcher JA, Rubin BP: KIT Mutations in GIST. Current Opinion in Genetics \& Development 2007, 17(I):3-7.

15. Wronski M, Ziarkiewicz-Wroblewska B, Gornika B, Cebulski W, Slodkowskj M, Wasiutynski A, Ktasnodebski IW: Synchronous occurrence of gastrointestinal stromal tumors and other primary gastrointestinal neoplasms. World ] Gastroenterol 2006, I 2(33):5360-5362.

16. Melis M, Choi EA, Anders R, Christiansen P, Fichera A: Synchronous colorectal adenocarcinoma and gastrointestinal stromal tumor (GIST). Int J Colorectal Dis 2007, 22: I09-I I4.

17. Kalmár K, Tornóczky T, Pótó L, Illényi L, Kalmár Nagy K, Kassai M, Kelemen D, Horváth OP: Gastrointestinal stromal tumors in a single institute: is there an association to other gastrointestinal malignancies? Magy Seb 2004, 57(5):25I-6.

18. Kövér E, Faluhelyi Z, Bogner B, Kalmár K, Horváth G, Tornóczky T: Dual tumors in the GI tract: synchronous and metachronous stromal (GIST) and epithelial/neuroendocrine neoplasms. Magy Onkol 2004, 48(4):3 I5-2I.

19. Abraham SC, Krasinskas AM, Hofstetter WL, Swisher SG, Wu TT: "Seedling" mesenchymal tumors (gastrointestinal stromal tumors and leiomyomas) are common incidental tumors of the esophagogastric junction. Am J Surg Pathol 2007, 3I(II):1629-35.

20. Blum MG, Bilimoria KY, Wayne JD, de Hoyos AL, Talamonti MS, Adley B: Surgical considerations for the management and resection of esophageal gastrointestinal stromal tumors. Ann Thorac Surg 2007, 84(5): 1723.
Publish with Bio Med Central and every scientist can read your work free of charge

"BioMed Central will be the most significant development for disseminating the results of biomedical research in our lifetime. "

Sir Paul Nurse, Cancer Research UK

Your research papers will be:

- available free of charge to the entire biomedical community

- peer reviewed and published immediately upon acceptance

- cited in PubMed and archived on PubMed Central

- yours - you keep the copyright
BioMedcentral 